\title{
The management of the painful bipartite patella: a systematic review
}

\author{
Samuel E. McMahon · Johannes A. LeRoux • \\ Toby O. Smith $\cdot$ Caroline B. Hing
}

\begin{abstract}
Purpose This study aimed to identify the most effective method for the treatment of the symptomatic bipartite patella. Methods A systematic review of the literature was completed, and all studies assessing the management of a bipartite patella were included. Owing to the paucity of randomised controlled trials, a narrative review of 22 studies was completed. A range of treatments were assessed: conservative measures, open and arthroscopic fixation or excision and soft tissue release and excision.

Results All of the methods provided results ranging from good to excellent, with acceptable complication rates.

Conclusions This is a poorly answered treatment question. No firm guidance can be given as to the most appropriate method of treating the symptomatic bipartite patella. This study suggests that there are a number of effective treatments with acceptable complication rates and it may be that treatments that conserve the patella are more appropriate for larger fragments.

Level of evidence IV.
\end{abstract}

S. E. McMahon (*)

Department of Trauma and Orthopaedics, Royal Victoria

Hospital, Belfast BT12 6BA, UK

e-mail: sammc84@gmail.com

J. A. LeRoux

Department of Trauma and Orthopaedics, Tygerberg Hospital,

Francie van Zijl Ave, Tygerberg, Cape Town 7505, South Africa

T. O. Smith

Faculty of Medicine and Health Sciences, University of East

Anglia, Norwich NR4 7TJ, UK

C. B. Hing

Department of Trauma and Orthopaedics, St George's University

London, Tooting, London SW17 0QT, UK
Keywords Patella $\cdot$ Bipartite $\cdot$ Multipartite

\section{Introduction}

The patella is the largest sesamoid bone in the human body. It develops initially as an expanding mass of cartilage with ossification beginning between the ages of 3 and 5 years and continuing until 9-10 years. In the majority of cases, multiple small foci combine to form a central nidus [18]. A single ossification centre is seen in $77 \%$ of children, and two or three centres seen in the remainder [22]. Usually, the centres unite to form a continuous subchondral plate. A bipartite patella therefore results from the failure of the ossification centres to unite, resulting in a fibrocartilaginous union between the bipartite fragment and patella body [4]. The incidence of a bipartite patella is reported as 1 to $2 \%$ in the population [16].

Saupe [23] described the most frequently used classification of bipartite patellae, which is based on the position of the accessory ossification centre. Type $1(5 \%)$ is characterised by a transverse split and the accessory centre at the inferior pole, in type $2(20 \%)$ there is a longitudinal split and the accessory centre is found at the lateral margin of the patella, and in type $3(75 \%)$ the accessory centre is found at the superolateral pole of the patella. However, Saupe's [23] classification has been criticised as it is only based on location of the accessory fragment. It does not take into account aetiology and does not cater for the tripartite patellae or the rare medial bipartite patella [20].

A bipartite patella is usually an incidental finding and can be hard to distinguish from a patella fracture [6]. Antero-posterior radiographs show a separated wellcorticated fragment in the majority of cases. 'Skyline' 
views can also be helpful [16]. Only $2 \%$ of patients have symptoms [26]. These usually comprise of anterior knee pain and tenderness on palpation of the accessory fragment. Pain is thought to be caused by fracture through, or separation of, the synchondrosis between the acces- sory fragment and patella, by direct trauma or repetitive stresses [10].

The large majority of cases are successfully managed with conservative treatments, such as rest, non-steroidal anti-inflammatory medication, immobilisation and physiotherapy, although there is no literature base to support this method of treatment. Surgical management is indicated when these methods have failed. Little is known with regard to the management of the persistently painful bipartite patella. This study aims to assess the evidence base regarding this management problem.

\section{Materials and methods}

\section{Eligibility}

Due to a paucity of randomised controlled trials identified from the initial literature search, any studies investigating the management of symptomatic bipartite patella were included. Studies published in any language were included, and papers were eligible irrespective of date of publication.

\section{Search strategy}

A PRISMA compliant [14] search of the published and unpublished literature was performed. The MeSH terms and Boolean operators used were 'bipartite', 'multipartite', 'patella' and 'patellae'.

Data and outcomes

Two reviewers (SM and JL) independently reviewed the full text of each paper included. Data extracted from each paper included the following: cohort age, gender mix, musculoskeletal history, clinical presentation, mechanism of injury, management strategy, outcome measures and follow-up period. The primary outcome measure was pain. Secondary outcome measures were the following: function, radiographic evidence of bone healing and satisfaction.

\section{Critical appraisal}

The Centre for Evidence-Based Management (CEBMa) critical appraisal tool for case studies and series was used to assess the methodological quality of the included studies. Each included paper was reviewed by one reviewer (SM) and verified by a second reviewer (JL).

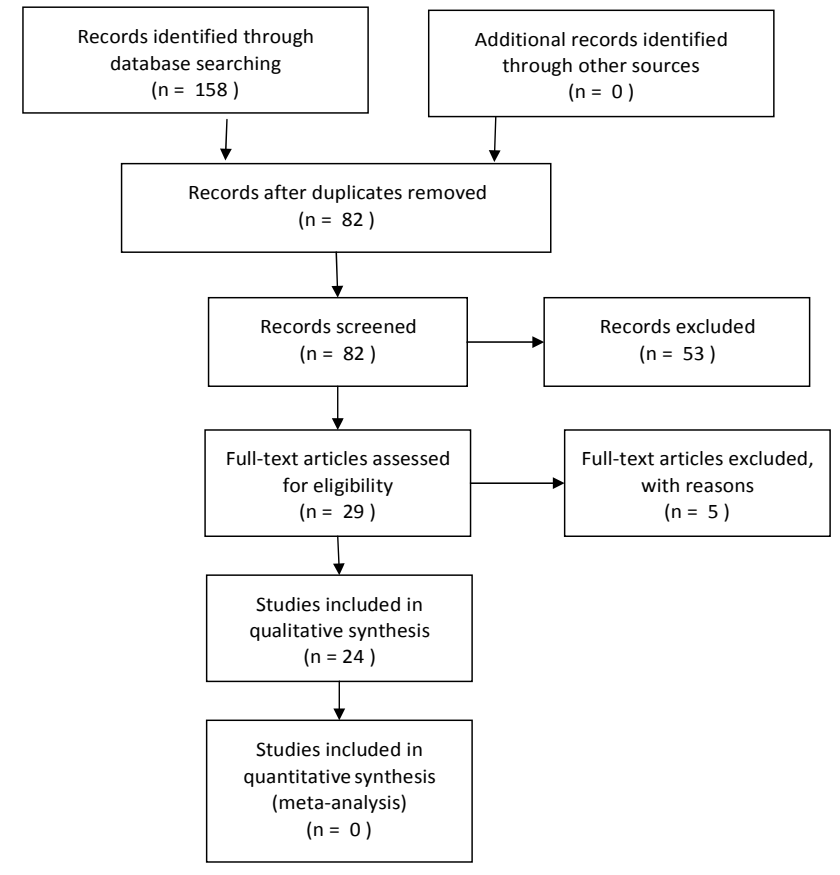

Fig. 1 PRISMA flow chart

Data analysis

The methodological approaches and data extracted were reviewed. There was significant cohort and study heterogeneity, principally based on management strategy and outcome assessments, which prevented us being able to undertake a meta-analysis. Therefore, a narrative review was deemed most appropriate and was undertaken to answer the research question.

\section{Results}

Search results

Twenty-two studies $[1-13,15,17,19,21,24,25,27-30]$ from an initial 82 were included for review. This comprised a total of 127 cases for review. The results of the search are presented in the PRISMA flow chart (Fig. 1). A summary of the study characteristics for each study is presented in Table 1.

Critical appraisal results

The critical appraisal can be found in Tables 2 and 3. The literature is dominated by level five evidence in the form of case reports and small case series. The methodological quality of these studies was assessed using the CEBMa critical appraisal tool. The quality of the studies was 
Table 1 Cohort characteristics

\begin{tabular}{|c|c|c|c|c|c|c|c|}
\hline Study & Study type & Treatment modality & No. of cases & $\begin{array}{l}\text { Mean age } \\
\text { (years) }\end{array}$ & Male/female & $\begin{array}{l}\text { Mean follow-up } \\
\text { (months) }\end{array}$ & Results \\
\hline Canizares [4] & Case report & $\begin{array}{l}\text { Operative: combined open/ } \\
\text { arthroscopic excision. }\end{array}$ & 1 & 32 & $1 / 0$ & 12 & Symptom free \\
\hline Ireland [10] & Case report & $\begin{array}{l}\text { Operative: diagnostic arthroscopy } \\
\text { followed by surgical excision }\end{array}$ & 1 & 46 & $1 / 0$ & 24 & Symptom free \\
\hline \multirow[t]{3}{*}{ Okuno [19] } & \multirow[t]{3}{*}{3 case reports } & Operative: tension band wiring & 1 & 16 & $1 / 0$ & 7 & Symptom free \\
\hline & & Conservative: immobilisation & 1 & 16 & $0 / 1$ & 4 & $\begin{array}{l}\text { Symptom free. Bone union on } \\
\text { X-ray }\end{array}$ \\
\hline & & Conservative: immobilisation & 1 & 16 & $0 / 1$ & 4 & $\begin{array}{l}\text { Symptom free. Bone union on } \\
\text { X-ray }\end{array}$ \\
\hline Stocker [24] & Case report & Conservative: immobilisation & 1 & 12 & $1 / 0$ & 12 & $\begin{array}{l}\text { Symptom free. Fracture healing on } \\
\text { MRI scan }\end{array}$ \\
\hline Wong [29] & Case report & Conservative: rest & 1 & 12 & $1 / 0$ & $>1.5$ & Symptom free \\
\hline Marya [13] & Case report & $\begin{array}{l}\text { Conservative: steroid and local } \\
\text { anaesthetic injection }\end{array}$ & 1 & 20 & $1 / 0$ & 24 & Symptom free \\
\hline \multirow[t]{2}{*}{ Kumahashi [12] } & \multirow[t]{2}{*}{2 case reports } & \multirow[t]{2}{*}{ Conservative: ultrasound therapy } & 1 & 13 & $1 / 0$ & 8 & $\begin{array}{l}\text { Symptom free. Bone union on } \\
\text { X-ray }\end{array}$ \\
\hline & & & $2(1 \mathrm{pt})$ & 13 & $1 / 0$ & 9 & $\begin{array}{l}\text { Symptom free bilaterally. Bone } \\
\text { union on right, narrowed gap on } \\
\text { the left. }\end{array}$ \\
\hline Azarbod [2] & Case report & Operative: arthroscopic excision & 1 & 26 & $1 / 0$ & 1.5 & Symptom free \\
\hline Carney [5] & Case report & Operative: arthroscopic excision & 1 & 19 & $1 / 0$ & 6 & Symptom free \\
\hline Felli [7] & Case report & Operative: arthroscopic excision & 1 & 23 & $0 / 1$ & 12 & Symptom free \\
\hline Iossifidis [9] & Case series & Operative: arthroscopic excision & $9(7 \mathrm{pts})$ & 30 & $4 / 3$ & 10 & $\begin{array}{l}6 \text { cases: symptom free } 3 \text { cases: } \\
\text { occasional pain }\end{array}$ \\
\hline \multirow[t]{3}{*}{ Werner [28] } & \multirow[t]{3}{*}{3 case reports } & Operative: arthroscopic excision & 1 & 16 & $1 / 0$ & 3 & Symptom free \\
\hline & & $\begin{array}{l}\text { Operative: open reduction internal } \\
\text { fixation }\end{array}$ & 1 & 21 & $1 / 0$ & 3 & Symptom free \\
\hline & & Operative: open surgical excision & 1 & 36 & $1 / 0$ & 2 & Symptom free \\
\hline Yoo [30] & Case report & Operative: arthroscopic excision & 1 & 37 & $1 / 0$ & NA & Symptom free \\
\hline Halpern [8] & Case report & Operative: surgical excision & 1 & 20 & $0 / 1$ & 12 & 'Significant relief' \\
\hline Ishikawa [11] & Case series & Operative: surgical excision & 9 & 16.8 & $9 / 0$ & 60 & $\begin{array}{l}\text { All symptom free. Six patients } \\
\text { required drainage of effusion }\end{array}$ \\
\hline Bourne [3] & Case series & Operative: surgical excision & 16 & 14.5 & $12 / 4 /$ & 84 & $\begin{array}{l}13 \text { Patients: complete recovery } 3 \\
\text { patients: occasional pain }\end{array}$ \\
\hline Weckström [27] & $\begin{array}{l}\text { Retrospective case } \\
\text { series }\end{array}$ & $\begin{array}{l}\text { Operative: surgical excision and } \\
\text { one arthroscopic excision }\end{array}$ & 25 & 20 & $25 / 0$ & 780 & $\begin{array}{l}\text { Kujala functional score }(0-100) \text { : } \\
\text { mean } 95(75-100) \text { VAS for pain } \\
(1-10) \text { : mean } 1(0-6)\end{array}$ \\
\hline
\end{tabular}


deemed of 'good' quality, with all scores ranging from eight to nine out of ten. Some of the studies neglected to state explicitly whether results were reviewed by more than one investigator.

\section{Conservative treatment}

The majority of cases of a symptomatic bipartite patella are treated conservatively. Surgical management is only considered in patients where this fails. We define conservative treatment as anything that does not require surgery.

Both Okuno et al. [19] and Stocker and Laer [24] assessed the effectiveness of immobilisation. In both studies, teenage patients suffered indirect patella trauma, with fracture across the bipartite synchondrosis. This was diagnosed by clinical findings and plain radiographs. Okuna et al. [19] immobilised two patients for 3 weeks followed by gradual resumption of sport. Both patients returned to full sporting activity within 3 months, and radiographic union of the bipartite fragment had occurred by 4 months follow-up. In a case study of one patient, Stocker and Laer [24] employed a longer course of treatment, with plaster of Paris for 2 weeks, a brace for 3 weeks and 12 weeks rest. This was followed by physiotherapy. Follow-up with magnetic resonance imaging (MRI) scan at 6 months showed a healed patella, with no symptoms.

Wong [29] reported a 12-year-old basketball and baseball player with anterior knee pain due to a bipartite patella diagnosed on plain radiographs. He was prescribed a 6week course of avoidance of painful activities and quadriceps strengthening. He was able to return to normal activities, although the length of follow-up was not specified.

Marya et al. [13] described a 20 years old with bilateral knee pain which persisted through rest and anti-inflammatory treatment. Three bupivicaine and methylprednisolone injections were given at 2-week intervals in each knee. He was asymptomatic at discharge with 2-year follow-up. Kumahashi et al. [12] undertook low-intensity pulsed ultrasound on two 13-year-old patients (one patient with bilateral bipartite patellae). Ultrasound therapy was conducted for 20 min each day. Both patients achieved complete resolution of symptoms at 8 and 9 months follow-up. Bone union was achieved in two of the three knees.

\section{Operative treatment}

\section{Arthroscopic excision}

Six studies assessed 12 patients who underwent arthroscopic excision as a treatment for symptomatic bipartite patella (Azarbod et al. [2], Carney et al. [5], Felli et al. [7], Iossifidis and Brueton [9], Werner et al. [28], Yoo et al. [30]). Although specific operative techniques varied; 
Table 2 CEBMa critical appraisal questionnaire



Table 3 CEBMa critical appraisal

\begin{tabular}{lccccccccccc}
\hline Study & 1 & 2 & 3 & 4 & 5 & 6 & 7 & 8 & 9 & 10 & Total \\
\hline Wong [29] & $\mathrm{Y}$ & $\mathrm{Y}$ & $\mathrm{Y}$ & $\mathrm{N}$ & $\mathrm{Y}$ & $\mathrm{Y}$ & $\mathrm{N}$ & $\mathrm{Y}$ & $\mathrm{Y}$ & $\mathrm{Y}$ & 8 \\
Marya [13] & $\mathrm{Y}$ & $\mathrm{Y}$ & $\mathrm{Y}$ & $\mathrm{N}$ & $\mathrm{Y}$ & $\mathrm{Y}$ & $?$ & $\mathrm{Y}$ & $\mathrm{Y}$ & $\mathrm{Y}$ & 8 \\
Kumahashi [12] & $\mathrm{Y}$ & $\mathrm{Y}$ & $\mathrm{Y}$ & $\mathrm{N}$ & $\mathrm{Y}$ & $\mathrm{Y}$ & $\mathrm{Y}$ & $\mathrm{Y}$ & $\mathrm{Y}$ & $\mathrm{Y}$ & 9 \\
Stocker [24] & $\mathrm{Y}$ & $\mathrm{Y}$ & $\mathrm{Y}$ & $\mathrm{N}$ & $\mathrm{Y}$ & $\mathrm{Y}$ & $\mathrm{Y}$ & $\mathrm{Y}$ & $\mathrm{Y}$ & $\mathrm{Y}$ & 9 \\
Azarbod [2] & $\mathrm{Y}$ & $\mathrm{Y}$ & $\mathrm{Y}$ & $\mathrm{N}$ & $\mathrm{Y}$ & $\mathrm{Y}$ & $\mathrm{Y}$ & $\mathrm{Y}$ & $\mathrm{Y}$ & $\mathrm{Y}$ & 9 \\
Felli [7] & $\mathrm{Y}$ & $\mathrm{Y}$ & $\mathrm{Y}$ & $\mathrm{N}$ & $\mathrm{Y}$ & $\mathrm{Y}$ & $\mathrm{Y}$ & $\mathrm{Y}$ & $\mathrm{Y}$ & $\mathrm{Y}$ & 9 \\
Carney [5] & $\mathrm{Y}$ & $\mathrm{Y}$ & $\mathrm{Y}$ & $\mathrm{N}$ & $\mathrm{Y}$ & $\mathrm{Y}$ & $\mathrm{Y}$ & $\mathrm{Y}$ & $\mathrm{Y}$ & $\mathrm{Y}$ & 9 \\
Iossifidis [9] & $\mathrm{Y}$ & $\mathrm{Y}$ & $\mathrm{Y}$ & $\mathrm{N}$ & $\mathrm{Y}$ & $\mathrm{Y}$ & $\mathrm{Y}$ & $\mathrm{Y}$ & $\mathrm{Y}$ & $\mathrm{Y}$ & 9 \\
Yoo [30] & $\mathrm{Y}$ & $\mathrm{Y}$ & $\mathrm{Y}$ & $\mathrm{N}$ & $\mathrm{Y}$ & $\mathrm{Y}$ & $\mathrm{Y}$ & $\mathrm{Y}$ & $\mathrm{Y}$ & $\mathrm{Y}$ & 9 \\
Canizares [4] & $\mathrm{Y}$ & $\mathrm{Y}$ & $\mathrm{Y}$ & $\mathrm{N}$ & $\mathrm{Y}$ & $\mathrm{Y}$ & $?$ & $\mathrm{Y}$ & $\mathrm{Y}$ & $\mathrm{Y}$ & 8 \\
Bourne [3] & $\mathrm{Y}$ & $\mathrm{Y}$ & $\mathrm{Y}$ & $\mathrm{N}$ & $\mathrm{Y}$ & $\mathrm{Y}$ & $\mathrm{Y}$ & $\mathrm{Y}$ & $\mathrm{Y}$ & $\mathrm{Y}$ & 9 \\
Halpern [8] & $\mathrm{Y}$ & $\mathrm{Y}$ & $\mathrm{Y}$ & $\mathrm{N}$ & $\mathrm{Y}$ & $\mathrm{Y}$ & $?$ & $\mathrm{Y}$ & $\mathrm{Y}$ & $\mathrm{Y}$ & 8 \\
Ireland [10] & $\mathrm{Y}$ & $\mathrm{Y}$ & $\mathrm{Y}$ & $\mathrm{N}$ & $\mathrm{Y}$ & $\mathrm{Y}$ & $?$ & $\mathrm{Y}$ & $\mathrm{Y}$ & $\mathrm{Y}$ & 8 \\
Ishikawa [11] & $\mathrm{Y}$ & $\mathrm{Y}$ & $\mathrm{Y}$ & $\mathrm{N}$ & $\mathrm{Y}$ & $\mathrm{Y}$ & $\mathrm{Y}$ & $\mathrm{Y}$ & $\mathrm{Y}$ & $\mathrm{Y}$ & 9 \\
Weckstrom [27] & $\mathrm{Y}$ & $\mathrm{Y}$ & $\mathrm{Y}$ & $\mathrm{N}$ & $\mathrm{Y}$ & $\mathrm{Y}$ & $\mathrm{Y}$ & $\mathrm{Y}$ & $\mathrm{Y}$ & $\mathrm{Y}$ & 9 \\
Ogata [17] & $\mathrm{Y}$ & $\mathrm{Y}$ & $\mathrm{Y}$ & $\mathrm{N}$ & $\mathrm{Y}$ & $\mathrm{Y}$ & $\mathrm{N}$ & $\mathrm{Y}$ & $\mathrm{Y}$ & $\mathrm{Y}$ & 8 \\
Adachi [1] & $\mathrm{Y}$ & $\mathrm{Y}$ & $\mathrm{Y}$ & $\mathrm{N}$ & $\mathrm{Y}$ & $\mathrm{Y}$ & $\mathrm{Y}$ & $\mathrm{Y}$ & $\mathrm{Y}$ & $\mathrm{Y}$ & 9 \\
Mori [15] & $\mathrm{Y}$ & $\mathrm{Y}$ & $\mathrm{Y}$ & $\mathrm{N}$ & $\mathrm{Y}$ & $\mathrm{Y}$ & $\mathrm{Y}$ & $\mathrm{Y}$ & $\mathrm{Y}$ & $\mathrm{Y}$ & 9 \\
Peek [21] & $\mathrm{Y}$ & $\mathrm{Y}$ & $\mathrm{Y}$ & $\mathrm{N}$ & $\mathrm{Y}$ & $\mathrm{Y}$ & $?$ & $\mathrm{Y}$ & $\mathrm{Y}$ & $\mathrm{Y}$ & 8 \\
Tauber [25] & $\mathrm{Y}$ & $\mathrm{Y}$ & $\mathrm{Y}$ & $\mathrm{N}$ & $\mathrm{Y}$ & $\mathrm{Y}$ & $\mathrm{Y}$ & $\mathrm{Y}$ & $\mathrm{Y}$ & $\mathrm{Y}$ & 9 \\
Okuno [19] & $\mathrm{Y}$ & $\mathrm{Y}$ & $\mathrm{Y}$ & $\mathrm{N}$ & $\mathrm{Y}$ & $\mathrm{Y}$ & $\mathrm{Y}$ & $\mathrm{Y}$ & $\mathrm{Y}$ & $\mathrm{Y}$ & 9 \\
Werner [28] & $\mathrm{Y}$ & $\mathrm{Y}$ & $\mathrm{Y}$ & $\mathrm{N}$ & $\mathrm{Y}$ & $\mathrm{Y}$ & $\mathrm{Y}$ & $\mathrm{Y}$ & $\mathrm{Y}$ & $\mathrm{Y}$ & 9 \\
\hline & & & & & & & & & & & \\
\hline
\end{tabular}

generally, the bipartite fragment was confirmed during arthroscopy and excised using a bone shaver, radiofrequency electrode or curette.

Five of the papers $[2,5,7,28,30]$ were case studies, with a follow-up range of between 1.5 and 12 months (one paper did not specify [30]). All five of the patients included in these studies reported a complete resolution of symptoms at the time of final assessment. The other seven patients were reported in a single study [9]. After a mean follow-up of 10 months (3-36), four patients were free of symptoms, and three had occasional knee ache, with no functional deficiency.

\section{Combined arthroscopic and surgical excision}

Canizares and Selesnick [4] and Werner et al. [28] described a technique that combined arthroscopy with open excision of the identified fragment. In both case studies, the patient had a type 3 bipartite patella. Initially, a standard arthroscopy was conducted followed by an incision over the superolateral aspect of the patella down to the bipartite patella fragment. The attached soft tissues were released, and the fragment was excised under direct vision. Canizares and Selesnick [4] found that their patient was free of symptoms by 1 month and able to resume sport at 7 weeks. 
Werner et al. [28] reviewed their patient 2 months postoperatively and reported a significant reduction in pain and that the patient had returned to running.

\section{Surgical excision}

Open surgical excision is the most widely reported method of treating a refractory symptomatic bipartite patella. Five studies [3, 8, 10, 11, 27] included 52 patients. Halpern and Hewitt [8] were the first to report removal of a type 2 fragment in a 20-year-old female, with 'significant relief' reported after 12 months follow-up. No complications were reported. Ireland et al. [10] also reported a case study of a 47-year-old man who had a type 3 fragment removed following a diagnostic arthroscopy. The patient returned to full activity by 4 months and was asymptomatic at final follow-up.

Ishikawa et al. [11] studied nine young male athletes [mean age 16.8 years (range 14-21)]. These patients had suffered a minimum of 3 months of pain on knee flexion. After a mean follow-up of 60 months (21-145), all nine had achieved an 'excellent' recovery. Six patients required a post-operative effusion drainage, but this did not affect long-term results.

Bourne and Bianco [3] performed a case series of 16 patients (12 males and 4 females), with a mean age of 14.5 (11-19) years. In their detailed follow-up after 84 $(12-156)$ months, they reported an 'excellent' result in 13 of 16 patients. Three suffered occasional pain; however, all 16 had a full range of movement. One patient required a further lateral release to relieve symptoms, and one suffered minor wound dehiscence in the post-operative period.

Weckstrom et al's [27] larger retrospective study of 25 male military recruits [mean age 20 (range 18-27) years] also provided encouraging results. Six patients had a type 2 fragment, and 19 had a type 3 fragment. In the immediate post-operative period, two patients developed a synovitis that required aspiration in both and steroid injection in one, and one patient developed a superficial wound infection that required oral antibiotics. All recruits were able to resume full activities by 5 weeks. After an extended followup period of 180 months (120-264), the range of movement was full in all knees. They performed the Kujala functional score (0-100). The mean result was 95 (75-100), and a visual analogue score for pain (1-10) provided a mean result of $1(0-6)$.

\section{Tension band wiring}

Three case reports managed pain caused by bipartite patella by tension band wiring [19, 21, 25]. All three reports involved teenaged (12,16 and 18 years old) sports enthusiasts, with sudden onset of pain during sporting activity with no direct trauma. Examination revealed and acute effusion in all cases and a palpable defect in two cases. Radiographs revealed a transverse patella fracture consistent with rupture of a pre-existing Saupe type 1 bipartite patella in all. In each case, the fracture was repaired with a tension-band-wiring technique.

In two patients [21, 25], subsequent removal of hardware (at 4 and 6 months, respectively) was required due to tenderness over the knee. Peek and Barry [21] completed follow-up at 4 months and reported osseous union and good range of movement. Tauber et al. [25] reported some ongoing pain after extended exercise at 29 months. Okuno et al.'s [19] patient was back to sports at 3 months, and bone union was confirmed on X-ray.

\section{Open reduction internal fixation (ORIF)}

A single case report assessed the effectiveness of open reduction (ORIF) of an isolated painful bipartite patella. Werner et al. [28] reported a 21-year-old patient who underwent ORIF of a type 2 bipartite patella following 6 months of failed conservative treatment. The repair was conducted using two cannulated compression screws. By 6 weeks, the patient had resolution of pain, with X-rays at 12 weeks showing signs of healing of the fracture.

\section{Soft tissue release}

Adachi et al. [1] and Ogata et al. [17] reported case series that described the release of the insertion of vastus lateralis into the bipartite fragment. It was felt that the removal of the tensile force across the fibrous union would allow resolution of symptoms.

Adachi et al. [1] studied 17 patients with Saupe type 3 bipartite patellae who underwent release of the vastus lateralis muscle following at least 3 months of conservative treatment. Seven had open surgery, and ten had arthroscopic excision. The vastus lateralis was released from the bipartite fragment. They found that complete bone union had occurred in 11 patients and incomplete union in six, by 6 months. Thirteen patients were described as having an 'excellent' outcome and four a 'good' outcome.

The authors found that the arthroscopic group had a shorter duration of knee effusion post-operatively and a smaller loss of thigh circumference and that these patients were able to regain muscle strength more rapidly. However, there were no significant differences between the groups at the final follow-up of 1 year.

Ogata [17] assessed 13 patients (15 cases), who had a diagnostic arthroscopy followed by open surgical release of the vastus lateralis. In cases of severe fragment mobility, the fragment was excised. Fragment mobility was assessed 
intraoperatively. The surgeon manipulated the fragment and if a groove at the area of separation widened, it was considered to mobile and therefore excised. Six patients had a Saupe type 2 fragment, and nine had a type 3 fragment. All had undergone at least 3 months of failed conservative treatment. The five patients who had excision all returned to activities within 2 months, and four reported an 'excellent' result at follow-up (3-8 years).

Nine patients who had a release of a type 3 bipartite patella were all able to resume activities within 2 months and reported 'excellent' results at final follow-up (2-9 years) with osseous union seen in eight of nine. The three patients who had a release of a type 2 fragment had a slower recovery. Activities were resumed in 6 months, two patients had an 'excellent' result, and one had a 'good' result at final follow-up (3-4 years).

Mori et al. [15] investigated 16 cases. They performed an arthroscopy followed by excision of a segment of the lateral retinaculum. This method involved a $2-\mathrm{cm}$ longitudinal incision on the lateral aspect of the mid patella and subcutaneous removal of a strip of retinaculum $0.5-1 \mathrm{~cm}$ wide and 6-8 $\mathrm{cm}$ long, extending proximal to the end of the separated fragment, followed by immediate active quadriceps use. Following surgical release, bone union was achieved by 4 months in 11 patients, by 8 months in 15 , with one fragment failing to unite by the end of follow-up. Eleven patients had an 'excellent' result, with five describing their outcome as 'good'.

\section{Discussion}

The most important finding in this study was that there are a number of ways to adequately manage a persistently painful bipartite patella. Although there is no documented evidence base, it is accepted that in the majority of cases a symptomatic bipartite patella responds well to conservative therapies. In those patients where problems persist, a more invasive treatment is necessary. The amount of time that should be allowed for conservative treatment is not clear.

With regard to operative intervention, a single study [28] reported a good outcome following open reduction and internal fixation of a fragment and this may be particularly useful in cases where there is a large fragment, and removal may compromise the function of the knee. Tension band wiring may also be appropriate here; however, tenderness over the wires and subsequent removal of hardware was a problem $[21,25]$. Various types of soft tissue release were also performed $[1,15,17]$, with good results, which equally may be useful in cases where a large fragment is present. However, this is only appropriate in Saupe type 3 bipartite patellae. Adachi et al. [1] suggest that an arthroscopic procedure allows faster recovery and fewer postoperative complications.

The second category of interventions includes methods where the fragment is excised. This can either be done by an open procedure, arthroscopic procedure or a combined approach. All of the methods provided good results, with the majority of patients returning to an asymptomatic state by the time of final follow-up. Arthroscopy may have the benefits of allowing inspection of the knee for other pathology, and fewer post-operative complications, with synovitis and superficial wound infections reported in the open surgical studies.

Whilst the critical appraisal reported that the methodological quality of the evidence base should be regarded as 'good', this is in respect to case series and cohort study designs. The gold-standard trial design to investigate the effectiveness of interventions is the randomised controlled trial. No randomised controlled trials were identified in the search strategy. Accordingly, it is not possible to suggest what the optimal interventions are for people with bipartite patella. This is a major study limitation and should be addressed in future. However, given the low prevalence of this condition in the normal population, conducting such trials may be difficult. To address this, trials will need to be national, multi-centre in nature.

\section{Conclusions}

The data set with regard to the management of a symptomatic bipartite patella is poor. There are no randomised control trials, and the literature is dominated by case studies and small case series. Any conclusions drawn must be viewed with this in mind.

The amount of time that conservative treatment should be continued prior to considering further intervention is not clear. In those papers that state this interval, the majority specify at least 3 months, and this seems a sensible minimum.

There is no strong evidence to then suggest which intervention is then most appropriate. All of the methods reviewed described generally good results, with few complications. It may be that methods that conserve the bipartite fragment are more appropriate when the fragment is large, but this is not clear. It may also be that arthroscopic procedures result in fewer post-operative complications and comparable long-term results.

To identify any significant trends, a multi-centre randomised controlled trial is recommended.

Conflict of interest None. 


\section{References}

1. Adachi N, Ochi M, Yamaguchi H, Uchio Y, Kuriwaka M (2002) Vastus lateralis release for painful bipartite patella. Arthroscopy 18(4):404-441

2 Azarbod P, Agar G, Patel V (2005) Arthroscopic excision of a painful bipartite patella fragment. Arthroscopy 21(8):1006

3. Bourne MH, Bianco AJ (1990) Bipartite patella in the adolescent: results of surgical excision. J Pediatr Orthop 10:69-73

4. Canizares GH, Selesnick FH (2003) Bipartite patella fracture. Arthroscopy 19(2):215-217

5. Carney J, Thompson D, O'Daniel J, Cassidy J (2010) Arthroscopic excision of a painful bipartite patella fragment. Am J Orthop 39(1):40-43

6. Echeverria TS, Bersani FA (1980) Acute fracture simulating a symptomatic bipartite patella. Am J Sports Med 8(1):48-50

7. Felli L, Fiore M, Biglieni L (2011) Arthroscopic treatment of symptomatic bipartite patella. Knee Surg Sports Traumatol Arthrosc 19(3):398-399

8. Halpern AA, Hewitt O (1978) Painful medial bipartite patella. Clin Orthop Relat Res 134:180-181

9. Iossifidis A, Brueton RN (1995) Painful bipartite patella following injury. Injury 26:175-176

10. Ireland ML, Chang JL (1995) Acute fracture bipartite patella: case report and literature review. Med Sci Sports Exerc 27(3):299-302

11. Ishikawa H, Sakurai A, Hirata S, Ohno O, Kita K, Sato T, Kashiwagi D (1994) Painful bipartite patella in young athletes. The diagnostic value of skyline views in squatting position and surgical excision. Clin Orthop Relat Res 305:223-228

12. Kumahashi N, Uchio Y, Iwasa J, Kawasaki K, Adachi N, Ochi M (2007) Bone union of painful bipartite patella after treatment with low-intensity pulsed ultrasound: report of two cases. Knee 15:50-53

13. Marya KM, Yadav V, Devagan A, Kundu ZS (2003) Painful bilateral bipartite patellae - case report. Indian J Med Sci 57:66

14. Moher D, Liberati A, Tetzlaff J et al (2009) Preferred reporting items for systematic reviews and meta-analyses: the PRISMA statement. BMJ 339:b2535

15. Mori Y, Okumo H, Iketani H, Kuroki Y (1995) Efficacy of lateral retinacular release for painful bipartite patella. Am J Sports Med 23(1):13-18
16. O’Brien J, Murphy C, Halpenny G, McNeill G, Torreggiani WC (2011) Magnetic resonance imaging features of asymptomatic bipartite patella. Eur J Radiol 78:425-429

17. Ogata K (1994) Painful bipartite patella. A new approach to operative treatment. Bone Joint Surg Am 76(4):573-578

18. Ogden JA (1984) Radiology of postnatal skeletal development. X. Patella and tibial tuberosity. Skelet Radiol 11(4):246-257

19. Okuno H, Sugita T, Kawamata T, Ohnuma M, Yamada N, Yoshizumi Y (2004) Traumatic separation of a type I bipartite patella: a report of four knees. Clin Orthop 420:257-260

20. Oohashi Y, Koshino T, Oohashi Y (2010) Clinical features and classification of bipartite or tripartite patella. Knee Surg Sports Traumatol Arthrosc 18:1465-1469

21. Peek AC, Barry M (2012) Patella fracture in a boy with bilateral inferior pole bipartite patellae. Knee 19(5):716-718

22. Prakash S, Chopra SRK, Jit I (1979) Ossification of the human patella. J Anat Soc India 28:78-83

23. Saupe E (1921) Beitrag zur patella bipartita. Fortschr Rontgenstr 28:37-41

24. Stocker RL, van Laer L (2011) Injury of a bipartite patella in a young upcoming sportsman. Arch Orthop Trauma Surg 131:75-78

25. Tauber M, Matis N, Resch H (2007) Traumatic separation of an uncommon bipartite patella type: a case report. Knee Surg Sports Traumatol Arthrosc 15(1):83-88

26. Weaver JK (1977) Bipartite patellae as a cause of disability in the athlete. Am J Sports Med 5:137-143

27. Weckström M, Parviainen M, Pihlajamäki HK (2008) Excision of painful bipartite patella: good long-term outcome in young adults. Clin Orthop Relat Res 466(11):2848-2855

28. Werner S, Durkan M, Jones J, Quilici S, Crawford D (2013) Symptomatic bipartite patella: three subtypes, three representative cases. J Knee Surg 26(Suppl. 1):72-76

29. Wong CK (2009) Bipartite patella in a young athlete. J Orthop Sports Phys Ther 39(7):560

30. Yoo JH, Kim EH, Ryu HW (2008) Arthroscopic removal of separated bipartite patella causing snapping knee syndrome. Orthopaedics 31(7):717 